\section{Persistierende Pupillarmembran}
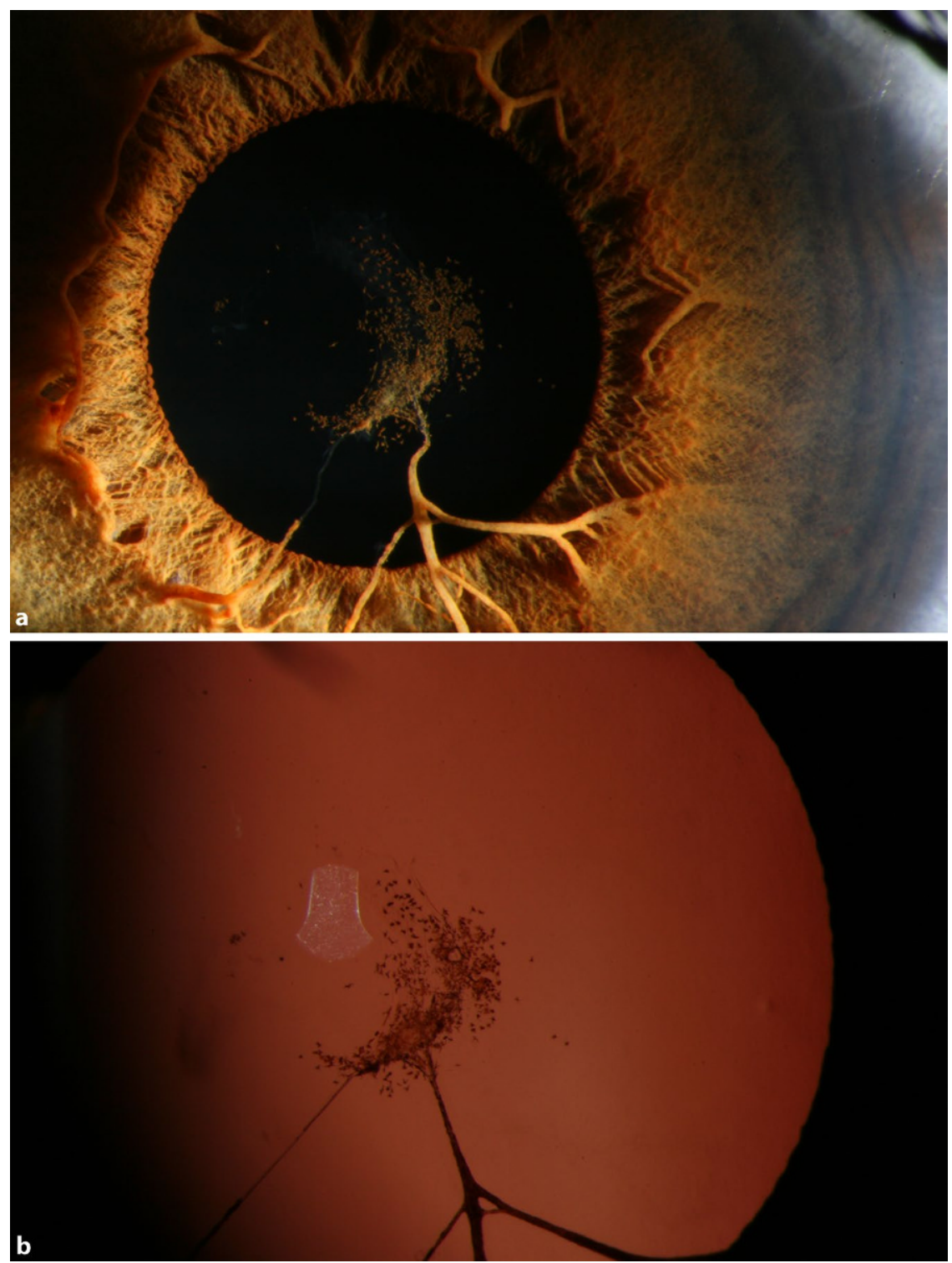

\ Geringfügig ausgeprägte, persistierende Pupillarmembran im seitlichen und regredienten Licht. Visus 0,8 bei höherer Hyperopie. Normalerweise kommt es zur kompletten Rückbildung der vorderen Tunica vasculosa lentis bis zum 8./9. Fetalmonat. Das klinische Spektrum der inkompletten Rückbildung reicht von einer deutlichen, u. U. erheblich Visus-limitierenden Membran bis zur "Abortivform" von lediglich zentral verbleibenden, sternförmigen Melanozyten, welche die Sehschärfe in der Regel nicht einschränken. Am häufigsten - und mit 10-20\% in der Bevölkerung keineswegs selten - sind verbleibende Fasern, welche immer an der Iriskrause, aber nie am Pupillarrand inserieren. In diesem Falle finden sich sowohl Fasern als auch „abortive melanozytäre Zellen“ im Pupillenzentrum

\section{Wir suchen Ihre informativen und überraschenden Bilder!}

Verlag und Herausgeberboard von Der Ophthalmologe laden Sie ein, die aufschlussreichsten Bilder aus Ihrem Alltag mit der Community zu teilen.

Schicken Sie uns Ihre Aufnahme, erklären Sie uns, wie es zu dem Bild kam und was Sie damit verbinden.

Eine Auswahl der informativsten Schnappschüsse wird dann, inklusive der Geschichte dahinter, in Der Ophthalmologe veröffentlicht. Wir freuen uns auf Ihre Beteiligung!

Senden Sie Ihre Bilder an:

Michal Meyer zu Tittingdorf

Managing Editor von Der Ophthalmologe

michal.meyerzutittingdorf@springer.com

\section{Korrespondenzadresse}

\section{Prof. Dr. Jens Martin Rohrbach}

Universitäts-Augenklinik

Elfriede-Aulhorn-Str. 7,

72076 Tübingen, Deutschland

Martin.Rohrbach@med.uni-tuebingen.de
Ophthalmologe $2021 \cdot 118: 981$

https://doi.org/10.1007/s00347-021-01496-0 (c) Springer Medizin Verlag $\mathrm{GmbH}$, ein Teil von Springer Nature 2021 